Pacific Journal of Mathematics

EVERY GENERALIZED PETERSEN GRAPH HAS A TAT 


\title{
EVERY GENERALIZED PETERSEN GRAPH HAS A TAIT COLORING
}

\author{
Frank Castagna and Geert Prins
}

\begin{abstract}
Watkins has defined a family of graphs which he calls generalized Petersen graphs. He conjectures that all but the original Petersen graph have a Tait coloring, and proves the conjecture for a large number of these graphs. In this paper it is shown that the conjecture is indeed true.
\end{abstract}

DeFINITIONS. Let $n$ and $k$ be positive integers, $k \leqq n-1, n \neq$ $2 k$. The generalized Petersen graph $G(n, k)$ has $2 n$ vertices, denoted by $\left\{0,1,2, \cdots, n-1 ; 0^{\prime}, 1^{\prime}, 2^{\prime}, \cdots, \cdots,(n-1)^{\prime}\right\}$ and all edges of the form $(i, i+1),\left(i, i^{\prime}\right),\left(i^{\prime},(i+k)^{\prime}\right)$ for $0 \leqq i \leqq n-1$, where all numbers are read modulo $n . G(5,2)$ is the Petersen graph. See Watkins [2].

The sets of edges $\{(i, i+1)\}$ and $\left\{\left(i^{\prime},(i+k)^{\prime}\right)\right\}$ are called the outer and inner rims respectively and the edges $\left(i, i^{\prime}\right)$ are called the spokes.

A Tait coloring of a trivalent graph is an edge-coloring in three colors such that each color is incident to each vertex. A 2-factor of a graph is a bivalent spanning subgraph. A 2-factor consists of disjoint circuits. A Tait cycle of a trivalent graph is a 2-factor all of whose circuits have even length. A Tait cycle induces a Tait coloring and conversely.

The method that Watkins used in proving that many generalized Petersen graphs have a Tait coloring was to prove that certain color patterns on the spokes induce a Tait coloring. Our method for the remaining cases consists of the construction of 2 -factors and of proof that these 2-factors are Tait cycles under appropriate conditions.

We restrict ourselves to the generalized Petersen graphs $G(n, k)$ with the properties:

$$
n \text { odd, } n \geqq 7,(n, k)=1 \text {, and } 2<k<\frac{n-1}{2} \text {. }
$$

All other cases (and some special instances of the above) were dealt with by Watkins.

We construct three types of 2-factors. The first type is a Tait cycle when $k$ is odd. The second type is a Tait cycle when $k$ is even and $n \equiv 3(\bmod 4)$ and also when $k$ is even and $n \equiv 1(\bmod 4)$ with $k^{-1}$ even. (As $(n, k)=1$, we define $k^{-1}$ as the unique positive integer $<n$, for which $k k^{-1} \equiv 1(\bmod n)$.) The third type takes care of the remaining graphs. 
The principal tool in the proofs is the automorphism $\varphi$ (henceforth fixed) of $G(n, k)$ defined by $\varphi(i)=n-i ; \varphi\left(i^{\prime}\right)=(n-i)$. In each case $\varphi$ induces an automorphism (also called $\varphi$ ) of the constructed 2 -factor. To facilitate notation we write $n=2 m+1$.

Construction 1. The subgraph $H$ of $G(n, k)$ has the following edges:

(a) On the outer rim: $(m+k, m+k+1),(m+k+1, m+\mathrm{k}+$ $2), \cdots,(n-1,0),(0,1),(1,2), \cdots,(m-k, m-k+1)$, $(m-k+2, m-k+3),(m-k+4, m-k+5), \cdots$, $(m+k-2, m+k-1)$.

The last line may be written as $(m-k+2 j, m-k+2 j+1)$, $1 \leqq j \leqq k-1$.

(b) Spokes: $\left(m+k,(m+k)^{\prime}\right),\left(m-k+1,(m-k+1)^{\prime}\right),(m-$ $\left.k+2,(m-k+2)^{\prime}\right), \cdots\left(m+k-1,(m+k-1)^{\prime}\right)$.

(c) On the inner rim: $\left(i^{\prime},(i+k)^{\prime}\right), m+1 \leqq i \leqq n-1$ $\left(i^{\prime},(i-k)^{\prime}\right), k \leqq i \leqq m$.

EXAMPLE. $G(11,3)$

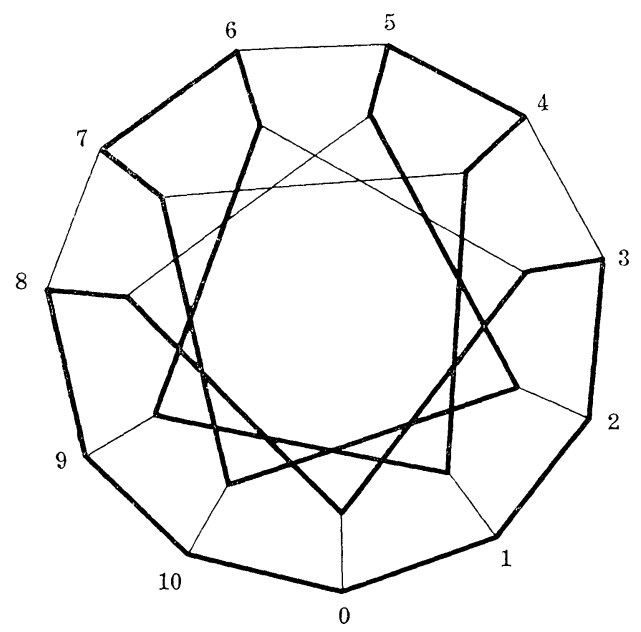

FIGURE 1

Clearly $H$ is a 2-factor, and $\varphi(H)=H$. If $C_{0}$ is the circuit of $H$ which contains 0 , then $\varphi\left(C_{0}\right)=C_{0}$. If $C_{0}$ has odd length, then it must contain an odd number of edges of the form $(i,-i)$ and $\left(i^{\prime},-i^{\prime}\right)$. The only candidates are:
(A) $(m, m+1)$
(B) $\left(\left(n-\frac{k}{2}\right)^{\prime},\left(\frac{k}{2}\right)^{\prime}\right)$
(C) $\left(\left(\frac{n-k}{2}\right)^{\prime},\left(\frac{n+k}{2}\right)^{\prime}\right)$. 
The edge $(C)$ is not in $H$ by our construction. Either the presence of (A) in $H$ or the existence of edge (B) will imply that $k$ is even. We conclude that if $k$ is odd $C_{0}$ has even length.

Let $m-k+2 \leqq i \leqq m+k-1$. Then either $i^{\prime}, i, i+1,(i+1)^{\prime}$ or $i^{\prime}, i, i-1,(i-1)^{\prime}$ are 4 consecutive vertices on a circuit of $H$. We call such sets 4 -sets. If every point of a circuit is on a 4 -set, then the circuit has even length.

Now consider a vertex $i^{\prime}, m+k<i \leqq n-1$ or $0 \leqq i<m-k+1$, which is not on $C_{0^{*}}$. The circuit of $H$ which contains $i^{\prime}$ passes consecutively through the the vertices $i^{\prime},(i+k)^{\prime},(i+2 k)^{\prime} \cdots(i+r k)^{\prime}$, $(i+(r+1) k)^{\prime}$, where $i+r k<m-k+1, i+(r+1) k>m-k+1$, $r \geqq 0$. The vertex $(i+(r+1) k)^{\prime}$ is on a 4 -set, and also $i+(r+1) k \leqq$ $m$, hence the circuit continues through the vertices $i+(r+1) k, i+$ $(r+1) k \pm 1,(i+(r+1) k \pm 1)^{\prime},(i+r k \pm 1)^{\prime} \cdots(i \pm 1)^{\prime}$. The circuit continues to $(i \pm 1-k)^{\prime}$ and by an identical argument eventually returns and hits $i^{\prime}$ or $(i+2)^{\prime}$ or $(i-2)^{\prime}$. In the first case the circuit is complete and it is easily seen that it has even length. The other two cases lead to a contradiction; for assume (w.l.o.g) that the circuit is on $\left(i^{\prime},(i+1)^{\prime},(i+2)^{\prime}\right)$. Then by the above argument the circuit will eventually hit either $(i+1)^{\prime}$ again or else $(i+3)^{\prime}$. But the first case is impossible, because $H$ is bivalent. Hence the circuit contains $(i+3)^{\prime}$ and further $(i+4)^{\prime} \cdots(m-k+1)^{\prime}$, but this contradicts our assumption, as $(m-k+1)^{\prime}$ is on $\mathrm{C}_{0}$.

Construction 2. $H$ has the following edges:

(a) On the outer rim: $(n-1,0),(0,1),(2,3), \cdots,(2 j, 2 j+1) \cdots$ $(n-3, n-2)$.

(b) Spokes: all, except $\left(0,0^{\prime}\right)$.

(c) On the inner rim: $\left(0^{\prime}, k^{\prime}\right),\left(2 k^{\prime}, 3 k^{\prime}\right), \cdots\left(2 j k^{\prime},(2 j+1) k^{\prime}\right), \cdots$, $\left((n-1) k^{\prime}, 0^{\prime}\right)$.

(For the sake of clarity we have written $c k^{\prime}$ instead of the formally more correct $(c k)^{\prime}$.)

Example. $G(15,4)$. See Figure 2.

Again, one checks easily that $H$ is a 2-factor and that $\varphi(H)=H$. Looking at the edges $(A),(B)$, and $(C)$ of Construction 1 , we note that $(C)$ is not an edge if $k$ is even. If edge $(A)$ occurs, then $m=$ $(n-1 /) 2$ is even and $n \equiv 1(\bmod 4)$. If edge $(B)$ occurs, and we write $k / 2 \equiv j k(\bmod n), j<n$, then $j$ is odd by our construction. But then $k \equiv 2 j k(\bmod n) \Rightarrow(2 j-1) \equiv 0(\bmod n) \Rightarrow n=2 j-1 \Rightarrow n \equiv 1(\bmod 4)$.

Hence if $n \equiv 3(\bmod 4)$ and $k$ is even none of the lines $(A),(B)$, and $(C)$ occur, and we may conclude by the argument used in Construction 1 that the circuits through 0 and $0^{\prime}$ have even length. All 


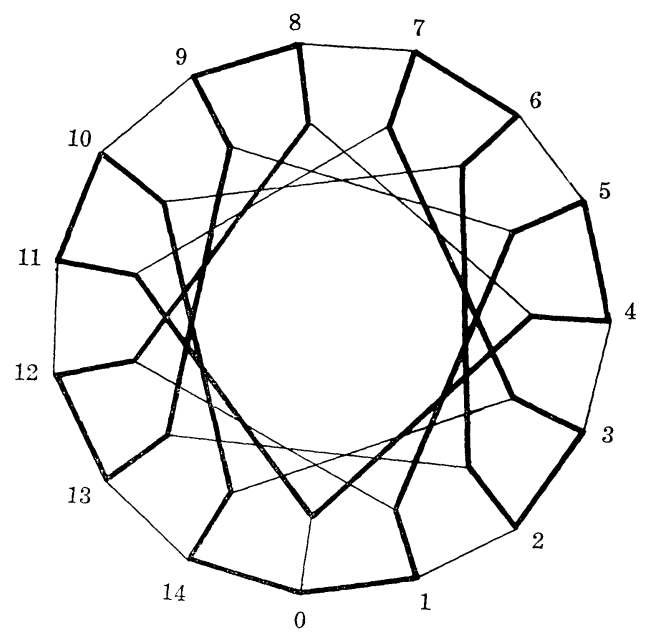

FIGURE 2

the points of every other circuit belong to a 4-set, and hence also have even length. Therefore $H$ if a Tait cycle if $n \equiv 3(\bmod 4)$ and $k$ is even.

If $n \equiv 1(\bmod 4)$ and $k$ and $k^{-1}$ are both even, then the edge $\left((k+1)^{\prime}, 1^{\prime}\right)=\left(1^{\prime},(k+1)^{\prime}\right)=\left(k^{-1} k^{\prime},\left(k^{-1}+1\right) k^{\prime}\right)$ exists in $H$, and so does the edge $\left(-1^{\prime},-(k+1)^{\prime}\right)$. We then obtain the circuit:

$$
\begin{aligned}
& 0^{\prime}, k^{\prime}, k, k+1,(k+1)^{\prime}, 1^{\prime}, 1,0,-1,-1^{\prime}, \\
& \quad-(k+1)^{\prime},-(k+1),-k,-k^{\prime}, 0^{\prime}
\end{aligned}
$$

which has length 14 and contains both 0 and $0^{\prime}$.

We conclude that in this case $H$ is again a Tait cycle.

Construction 3 . For this construction we assume $n \equiv 1(\bmod 4)$, $k$ even, $k^{-1}$ odd and $>n / 2$. This last assumption is no real restriction, because if $k^{-1}$ is odd and $<n / 2$, then Construction 1 gives a Tait cycle for $G\left(n, k^{-1}\right)$ and Watkins has shown that $G(n, k)$ and $G\left(n, k^{-1}\right)$ are isomorphic. Finally we need to assume $k>2$; this restriction was not needed in Constructions 1 and 2.

$H$ has the following edges:

On the outer rim: $(-1,0),(0,1),(2,3), \cdots,(k-4, k-3),(k-2$, $k-1),(k-1, k),(k+1, k+2), \cdots(n-k-2, n-k-1),(n-k, n-$ $k+1),(n-k+1, n-k+2),(n-k+3, n-k+4), \cdots,(n-3, n-2)$. Spokes: all except $\left(0^{\prime} 0^{\prime}\right),\left(k-1,(k-1)^{\prime}\right),\left(n-k+1,(n-k+1)^{\prime}\right)$.

On the inner rim: $\left(0^{\prime}, k^{\prime}\right),\left(2 k^{\prime}, 3 k^{\prime}\right), \cdots,\left(\left(n-k^{-1}\right) k^{\prime},\left(n-k^{-1}+\right.\right.$ $\left.\left.1) k^{\prime}\right),\left(\left(n-k^{-1}+1\right) k^{\prime},\left(n-k^{-1}+2\right) k^{\prime}\right),\left(\left(n-k^{-1}+3\right) k^{\prime},\left(n-k^{-1}+4\right) k^{\prime}\right)\right)$, $\cdots,\left(\left(k^{-1}-2\right) k^{\prime},\left(k^{-1}-1\right) k^{\prime}\right),\left(\left(k^{-1}-1\right) k^{\prime}, k^{-1} k^{\prime}\right),\left(\left(k^{-1}+1\right) k^{\prime},\left(k^{-1}+2\right) k^{\prime}\right)$, $\cdots,\left((n-1) k^{\prime}, 0^{\prime}\right)$. 
EXAmPLe. $G(17,4)$

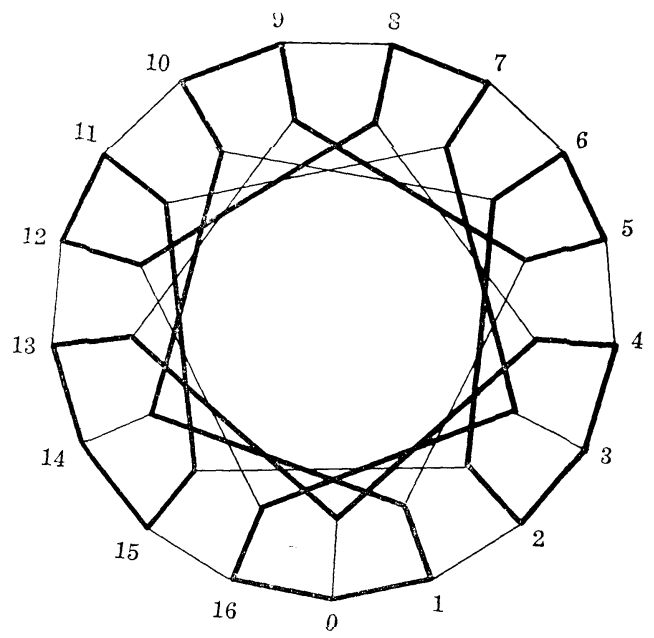

FIgURE 3

$H$ is a 2-factor, as long as $n-k^{-1}+1<k^{-1}-1$, which assures that the constructed edges on the inner rim cover all vertices of the inner rim. But this condition holds whenever $k^{-1}>(n+1 / 2)$ or altenatively when $k^{-1}>(n / 2)$, and $k>2$. It is clear that $\varphi(H)=H$.

Since $n \equiv 1(\bmod 4), m$ is even and $(m, m+1)$ is not an edge of $H$. As $(n-k /) 2$ is not an integer $H$ does not have an edge $((n-k) / 2)^{\prime}$, $\left.(n+k) / 2)^{\prime}\right)$. Finally, since $n-k^{-1}+1 \leqq(n-1) / 2=m<m+1=$ $(n+1) / 2 \leqq k^{-1}-1$, and $m$ is even, $H$ does not contain the edge $\left(m k^{\prime},(m+1) k^{\prime}\right)=\left(-k^{\prime} / 2, k^{\prime} / 2\right)$. As before we conclude that the circuits containing 0 and $0^{\prime}$ have even length. The circuit containing 0 also contains $n-1,(n-1)^{\prime},(k-1)^{\prime}$ and $1,1^{\prime},(n-k+1)^{\prime}$, while the circuit containing $0^{\prime}$ also contains $k^{\prime}, k, k-1, k-2,(k-2)^{\prime}$ and $(n-k)^{\prime}, n-k, n-k+1, n-k+2,(n-k+2)^{\prime}$. Hence the other circuits only contain vertices of 4 -sets and every circuit of $H$ has even length.

We note that our constructions are not mutually exclusive. For example, Construction 1 also produces a Tait cycle, when $k$ is even, and the largest positive integer $q$ such that $q k<n$ is an odd number.

We conclude with a new conjecture. G. N. Robertson [1] has shown that $G(n, 2)$ is Hamiltonian unless $n \equiv 5(\bmod 6)$. As $G(n, 2) \cong$ $G(n,(n+1) / 2) \cong G(n,(n-1) / 2) \cong G(n, n-2)$ (see [2]), none of these graphs has a Hamiltonian if $n \equiv 5(\bmod 6)$. We conjecture that all other generalized Petersen graphs are Hamiltonian. In all examples that we have worked out $G(n, k)$ possesses a Hamiltonian $H$ with $\varphi(H)=H$, but our three constructions are Hamiltonians only in a minority of cases. 


\section{REFERENCES}

1. G. N. Robertson, Graphs under Girth, Valency, and Connectivity Constraints (Dissertation), University of Waterloo, Waterloo, Ontario, Canada, 1968.

2. Mark E. Watkins, A theorem on Tait colorings with an application to the generalized Petersen graphs, J. Combinatorial Theory, 6 (1969), 152-164.

Received June 16, 1970 and in revised form August 20, 1970.

Wayne State University 


\section{PACIFIC JOURNAL OF MATHEMATICS}

\section{EDITORS}

H. SAMELSON

Stanford University

Stanford, California 94305

C. R. HOBBY

University of Washington

Seattle, Washington 98105
J. DugundJI

Department of Mathematics

University of Southern California

Los Angeles, California 90007

RICHARD ARENS

University of California

Los Angeles, California 90024

\section{ASSOCIATE EDITORS}

E. F. BeCKENBACH

B. H. NeumanN

F. WOLF

K. YosHIDA

\section{SUPPORTING INSTITUTIONS}

UNIVERSITY OF BRITISH COLUMBIA

CALIFORNIA INSTITUTE OF TECHNOLOGY

UNIVERSITY OF CALIFORNIA

MONTANA STATE UNIVERSITY

UNIVERSITY OF NEVADA

NEW MEXICO STATE UNIVERSITY

OREGON STATE UNIVERSITY

UNIVERSITY OF OREGON

OSARA UNIVERSITY
UNIVERSITY OF SOUTHERN CALIFORNIA STANFORD UNIVERSITY

UNIVERSITY OF TOKYO

UNIVERSITY OF UTAH

WASHINGTON STATE UNIVERSITY

UNIVERSITY OF WASHINGTON

AMERICAN MATHEMATICAL SOCIETY

NAVAL WEAPONS CENTER

Printed in Japan by International Academic Printing Co., Ltd., Tokyo, Japan 


\section{Pacific Journal of Mathematics}

\section{Vol. 40, No. $1 \quad$ September, 1972}

Alex Bacopoulos and Athanassios G. Kartsatos, On polynomials

approximating the solutions of nonlinear differential equations........

Monte Boisen and Max Dean Larsen, Prüfer and valuation rings with zero

divisors ..........................................

James J. Bowe, Neat homomorphisms

David W. Boyd and Hershy Kisilevsky, The Diophantine equation

$$
u(u+1)(u+2)(u+3)=v(v+1)(v+2) \ldots \ldots \ldots \ldots \ldots \ldots \ldots
$$

George Ulrich Brauer, Summability and Fourier analysis ...............

Robin B. S. Brooks, On removing coincidences of two maps when only one,

rather than both, of them may be deformed by a homotopy ............

Frank Castagna and Geert Caleb Ernst Prins, Every generalized Petersen

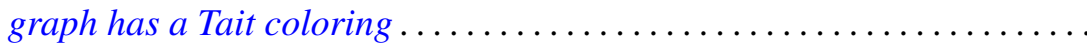

Micheal Neal Dyer, Rational homology and Whitehead products ..........

John Fuelberth and Mark Lawrence Teply, The singular submodule of a

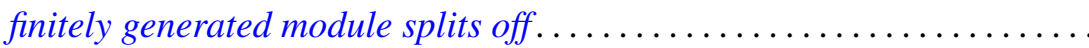

Robert Gold, $\Gamma$-extensions of imaginary quadratic fields ............ 83

Myron Goldberg and John W. Moon, Cycles in k-strong tournaments.......

Darald Joe Hartfiel and J. W. Spellmann, Diagonal similarity of irreducible

matrices to row stochastic matrices...............

Wayland M. Hubbart, Some results on blocks over local fields ..

Alan Loeb Kostinsky, Projective lattices and bounded homomorphisms....

Kenneth O. Leland, Maximum modulus theorems for algebras of operator

valued functions ...

Jerome Irving Malitz and William Nelson Reinhardt, Maximal models in the

language with quantifier "there exist uncountably many" ..

John Douglas Moore, Isometric immersions of space forms in space

forms.

Ronald C. Mullin and Ralph Gordon Stanton, A map-theoretic approach to

Davenport-Schinzel sequences ....................

Chull Park, On Fredholm transformations in Yeh-Wiener space. .

Stanley Poreda, Complex Chebyshev alterations ..............

Ray C. Shiflett, Extreme Markov operators and the orbits of Ryff. ...

Robert L. Snider, Lattices of radicals .....................

Ralph Richard Summerhill, Unknotting cones in the topological

category ................................

Charles Irvin Vinsonhaler, A note on two generalizations of $\mathrm{QF}-3 \ldots \ldots 229$

William Patterson Wardlaw, Defining relations for certain integrally

parameterized Chevalley groups...................

William Jennings Wickless, Abelian groups which admit only nilpotent

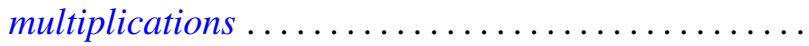

